\title{
Evaluation of the Japanese Gastric Cancer Association's Gastric Cancer Treatment Guidelines for Popular Use
}

\author{
Takashi Ichikura, Toshiya Ogawa, Takashi Majima, Susumu Saigusa, Yoshinisa Yaguchi, Naoko Sakamoto, \\ and HideTaKa Mochizuki
}

First Department of Surgery, National Defense Medical College Hospital, 3-2 Namiki, Tokorozawa 359-8513, Japan

\begin{abstract}
Background. The Japanese Gastric Cancer Association's (JGCA's) Gastric cancer treatment guidelines for doctors' reference and the guidelines (GLs) for popular use were both published in 2001. The purpose of this study was to know whether or not it is useful for patients to read the GLs for popular use.

Methods. We lent the GLs for popular use to patients with gastric cancer for several days and had them read the GLs before they were informed about their condition and the recommended treatment. Then they received questionnaires concerning the GLs.

Results. Most of the patients, even the elderly, had read and understood the GLs. Nearly $70 \%$ of the patients answered that it was very useful for them to read the GLs. On the other hand, 34\% of the patients suggested negative aspects, such that reading the GLs increased their anxiety about the disease or treatment. Only $9 \%$ of the patients expected treatment that followed the GLs, whereas $54 \%$ of the patients expected treatment based on the doctor's own experience without adherence to the GLs. If the doctor were to suggest treatment that did not follow the GLs, $87 \%$ of the patients answered that they would follow the doctor's suggestion, and it was only $8 \%$ who answered that they would seek a second opinion. These results did not differ when patients were requested to fill out questionnaires anonymously.

Conclusion. Although the GLs for popular use are useful to provide patients with information concerning the disease and the treatment modalities, they may not have a great impact on patients' decisions about their treatment.
\end{abstract}

Key words Gastric cancer · Treatment guidelines · Second opinion

Offprint requests to: T. Ichikura

Received: September 17, 2003 / Accepted: November 10, 2003
Introduction

Gastric cancer treatment guidelines for doctors' reference [1] and guidelines (GLs) for popular use [2] were published by the Japanese Gastric Cancer Association in March 2001 and December 2001, respectively. An outline of the GLs for doctors' reference is available in English online [3], although English versions of the GLs are not yet published. It is stated that the purpose of the GLs is to reduce differences in treatment selection by institutions and doctors and to improve mutual understanding on the extent of disease and treatment modalities between doctors and patients. Although both doctors and patients have to read the GLs for the latter purpose, most patients do not even know of the existence of the GLs. Therefore, we started a program to have patients with gastric cancer read the GLs for popular use. The purpose of this study, carried out by a questionnaire survey, was to know whether or not it is useful for patients to read the GLs.

\section{Methods}

A total of 97 patients were admitted to the First Department of Surgery, National Defense Medical College Hospital, Tokorozawa, Japan, for the treatment of gastric cancer in the period between February 2002 and April 2003. We lent the GLs for popular use to the patients for several days, and had them read the GLs. Then they received questionnaires concerning the GLs (Tables 1-7). When they answered the questionnaires, the patients had been informed only that they had gastric cancer, and the extent of disease and the recommended treatment were explained afterward. Patients who were admitted before November 2002 were requested to answer the questionnaires with their signature. Patients who were admitted after November 2002 were requested to fill out the questionnaires 
Table 1. Answers to the question, "Did you read the guidelines?"

\begin{tabular}{lcccc}
\hline & $\begin{array}{c}\text { Yes, almost } \\
\text { all }\end{array}$ & $\begin{array}{c}\text { Yes, more } \\
\text { than half }\end{array}$ & $\begin{array}{c}\text { Yes, some } \\
\text { part }\end{array}$ & No \\
\hline $\begin{array}{l}\text { Age (years) } \\
\leqq 59\end{array}$ & $16(94 \%)$ & 0 & $1(6 \%)$ & 0 \\
$\begin{array}{l}\text { 60-69 } \\
\geqq 70\end{array}$ & $14(82 \%)$ & $3(18 \%)$ & 0 & 0 \\
Sex & $9(75 \%)$ & $1(8 \%)$ & $2(17 \%)$ & 0 \\
$\quad$ Male & $29(88 \%)$ & $4(12 \%)$ & 0 & 0 \\
Female & $10(77 \%)$ & 0 & $3(23 \%)$ & 0 \\
Tumor stage & $19(86 \%)$ & $1(5 \%)$ & $2(9 \%)$ & 0 \\
$\quad$ T1 & $20(83 \%)$ & $3(11 \%)$ & $1(4 \%)$ & 0 \\
$\quad$ T2-4 & $19(90 \%)$ & 0 & 0 & $2(10 \%)$ \\
Anonymous & $58(87 \%)$ & $4(6 \%)$ & $3(4 \%)$ & $2(3 \%)$ \\
Total & & & & \\
\hline
\end{tabular}

Table 2. Answers to the question, "Did you understand the content of the guidelines?"

\begin{tabular}{lcccr}
\hline & $\begin{array}{c}\text { Yes, almost } \\
\text { all }\end{array}$ & $\begin{array}{c}\text { Yes, more } \\
\text { than half }\end{array}$ & $\begin{array}{c}\text { Yes, some } \\
\text { part }\end{array}$ & No \\
\hline $\begin{array}{l}\text { Age (years) } \\
\leqq 59\end{array}$ & $11(65 \%)$ & $3(18 \%)$ & $3(18 \%)$ & 0 \\
$60-69$ & $8(47 \%)$ & $4(24 \%)$ & $5(29 \%)$ & 0 \\
$\geqq 70$ & $6(50 \%)$ & $4(33 \%)$ & $2(17 \%)$ & 0 \\
Sex & & & & 0 \\
Male & $19(58 \%)$ & $10(30 \%)$ & $4(12 \%)$ & 0 \\
Female & $6(46 \%)$ & $1(8 \%)$ & $6(46 \%)$ & 0 \\
Tumor stage & $11(50 \%)$ & $6(27 \%)$ & $5(23 \%)$ & 0 \\
T1 & $14(58 \%)$ & $5(21 \%)$ & $5(21 \%)$ & 0 \\
$\quad 12-4$ & $12(67 \%)$ & $5(28 \%)$ & $1(6 \%)$ & 0 \\
Anonymous & $37(58 \%)$ & $16(25 \%)$ & $11(17 \%)$ & 0 \\
Total & & & & \\
\hline
\end{tabular}

Table 3. Answers to the question, "Did you have any knowledge about the content of the guidelines before you read them?"

\begin{tabular}{|c|c|c|c|c|}
\hline & $\begin{array}{l}\text { Yes, almost } \\
\text { all }\end{array}$ & $\begin{array}{l}\text { Yes, more } \\
\text { than half }\end{array}$ & $\begin{array}{l}\text { Yes, a } \\
\text { little }\end{array}$ & No \\
\hline \multicolumn{5}{|l|}{ Age (years) } \\
\hline$\leqq 59$ & 0 & 0 & $10(59 \%)$ & $7(41 \%)$ \\
\hline $60-69$ & 0 & $1(6 \%)$ & $7(41 \%)$ & $9(53 \%)$ \\
\hline$\geqq 70$ & $1(8 \%)$ & $1(8 \%)$ & $4(33 \%)$ & $6(50 \%)$ \\
\hline \multicolumn{5}{|l|}{ Sex } \\
\hline Male & $1(3 \%)$ & $2(6 \%)$ & $14(42 \%)$ & $16(48 \%)$ \\
\hline Female & 0 & 0 & $7(54 \%)$ & $6(46 \%)$ \\
\hline \multicolumn{5}{|l|}{ Tumor stage } \\
\hline $\mathrm{T} 1$ & 0 & 0 & $10(45 \%)$ & $12(55 \%)$ \\
\hline $\mathrm{T} 2-4$ & $1(4 \%)$ & $2(8 \%)$ & $11(46 \%)$ & $10(42 \%)$ \\
\hline Anonymous & $1(5 \%)$ & $2(11 \%)$ & $10(53 \%)$ & $6(32 \%)$ \\
\hline Total & $2(3 \%)$ & $4(6 \%)$ & $31(48 \%)$ & $28(43 \%)$ \\
\hline
\end{tabular}


Table 4. Answers to the question, "Is it useful for you to read the guidelines before treatment?"

\begin{tabular}{|c|c|c|c|c|}
\hline & $\begin{array}{l}\text { Yes, very } \\
\text { much }\end{array}$ & $\begin{array}{c}\text { Yes, to } \\
\text { some degree }\end{array}$ & Not really & Not at all \\
\hline \multicolumn{5}{|l|}{ Age (years) } \\
\hline$\leqq 59$ & $14(82 \%)$ & $3(18 \%)$ & 0 & 0 \\
\hline $60-69$ & $10(59 \%)$ & $7(41 \%)$ & 0 & 0 \\
\hline$\geqq 70$ & $9(75 \%)$ & $2(17 \%)$ & $1(8 \%)$ & 0 \\
\hline Sex & & & & 0 \\
\hline Male & $23(70 \%)$ & $10(30 \%)$ & 0 & 0 \\
\hline Female & $10(77 \%)$ & $2(15 \%)$ & $1(8 \%)$ & 0 \\
\hline \multicolumn{5}{|l|}{ Tumor stage } \\
\hline $\mathrm{T} 1$ & $17(77 \%)$ & $4(18 \%)$ & $1(5 \%)$ & 0 \\
\hline $\mathrm{T} 2-4$ & $16(67 \%)$ & $8(33 \%)$ & 0 & 0 \\
\hline Anonymous & $11(61 \%)$ & $7(39 \%)$ & 0 & 0 \\
\hline Total & $44(69 \%)$ & $19(30 \%)$ & $1(2 \%)$ & 0 \\
\hline
\end{tabular}

Table 5. Answers to the question, "Are there any disadvantages in reading the guidelines before treatment?"

\begin{tabular}{lcccc}
\hline & No & Confusing & Increases anxiety & Others \\
\hline $\begin{array}{l}\text { Age (years) } \\
\leqq 59\end{array}$ & $13(76 \%)$ & $1(6 \%)$ & $3(18 \%)$ & 0 \\
$\quad 90-69$ & $9(53 \%)$ & 0 & $6(35 \%)$ & $2(12 \%)$ \\
$\geqq 70$ & $9(75 \%)$ & $1(8 \%)$ & $2(17 \%)$ & 0 \\
Sex & & & & $2(27 \%)$ \\
$\quad$ Male & $22(67 \%)$ & 0 & $2(15 \%)$ & 0 \\
Female & $9(69 \%)$ & $2(15 \%)$ & $6(27 \%)$ & 0 \\
Tumor stage & & & $5(21 \%)$ & $2(8 \%)$ \\
$\quad$ T1 & $16(73 \%)$ & 0 & $4(25 \%)$ & $1(6 \%)$ \\
$\quad$ T2-4 & $15(63 \%)$ & $2(8 \%)$ & $15(24 \%)$ & $3(5 \%)$ \\
Anonymous & $10(63 \%)$ & $1(6 \%)$ & & 0 \\
Total & $41(66 \%)$ & $3(5 \%)$ & & \\
\hline
\end{tabular}

Table 6. Answers to the question, "What kind of treatment do you expect?"

\begin{tabular}{|c|c|c|c|c|}
\hline & Following GLs ${ }^{\mathrm{a}}$ & Following GLs + some $\mathrm{CT}^{\mathrm{b}}$ & $\mathrm{CT}+\mathrm{GLs}^{\mathrm{c}}$ & Doctor's experience ${ }^{d}$ \\
\hline \multicolumn{5}{|l|}{ Age (years) } \\
\hline$\leqq 59$ & $1(7 \%)$ & $5(33 \%)$ & $1(7 \%)$ & $8(53 \%)$ \\
\hline $60-69$ & $1(6 \%)$ & $6(38 \%)$ & $1(6 \%)$ & $8(50 \%)$ \\
\hline$\geqq 70$ & $2(17 \%)$ & $2(17 \%)$ & 0 & $8(67 \%)$ \\
\hline \multicolumn{5}{|l|}{ Sex } \\
\hline Male & $4(13 \%)$ & $11(34 \%)$ & $1(3 \%)$ & $16(50 \%)$ \\
\hline Female & 0 & $2(18 \%)$ & $1(9 \%)$ & $8(73 \%)$ \\
\hline \multicolumn{5}{|l|}{ Tumor stage } \\
\hline $\mathrm{T} 1$ & $3(16 \%)$ & $7(37 \%)$ & $1(5 \%)$ & $8(42 \%)$ \\
\hline $\mathrm{T} 2-4$ & $1(4 \%)$ & $6(25 \%)$ & $1(4 \%)$ & $16(67 \%)$ \\
\hline Anonymous & $1(7 \%)$ & $5(36 \%)$ & $1(7 \%)$ & $7(50 \%)$ \\
\hline Total & $5(9 \%)$ & $18(32 \%)$ & $3(5 \%)$ & $31(54 \%)$ \\
\hline
\end{tabular}

a Treatment following the guidelines (GLs)

${ }^{\mathrm{b}}$ Treatment basically following the GLs, adopting some clinical trial (CT)-based treatment

c Adopting CT-based treatment enthusiastically, taking the GLs into consideration to some extent

dTreatment based on the doctor's own experience, without adhering to the GLs 
Table 7. Answers to the question, "How would you respond if your doctor suggested treatment that did not follow the guidelines?"

\begin{tabular}{lcccc}
\hline & Doctor's suggestion $^{\mathrm{a}}$ & Follow GL $^{\mathrm{b}}$ & Second opinion $^{\mathrm{c}}$ & Other $^{\mathrm{d}}$ \\
\hline $\begin{array}{l}\text { Age (years) } \\
\leqq 59\end{array}$ & $14(82 \%)$ & 0 & $2(12 \%)$ & $1(6 \%)$ \\
$\quad 13-69$ & $12(100 \%)$ & $1(6 \%)$ & $2(12 \%)$ & $1(6 \%)$ \\
$\quad \geqq 70$ & 0 & 0 & 0 \\
Sex & $29(88 \%)$ & $1(3 \%)$ & $3(9 \%)$ & 0 \\
$\quad$ Male & $10(77 \%)$ & 0 & $1(8 \%)$ & $2(15 \%)$ \\
Female & $19(86 \%)$ & $1(5 \%)$ & $1(5 \%)$ & $1(5 \%)$ \\
Early? & $20(83 \%)$ & 0 & $3(13 \%)$ & $1(4 \%)$ \\
T1 & $13(93 \%)$ & 0 & $1(7 \%)$ & 0 \\
$\quad$ T2-4 & $52(87 \%)$ & $1(2 \%)$ & $5(8 \%)$ & $2(3 \%)$ \\
Anonymous & & & & \\
Total & & & & \\
\hline
\end{tabular}

a I would follow the doctor's suggestion

${ }^{\mathrm{b}}$ I would prefer treatment that followed the guidelines

${ }^{\mathrm{c}}$ I would seek a second opinion

${ }^{d}$ Other

anonymously and drop them into a box prepared for this survey, so that we could not identify the respondents. Patients with a poor understanding due to dementia and those who underwent emergency surgery due to bleeding or obstruction were excluded from this study. Some patients dropped out because they were, mistakenly, not given a questionnaire.

If respondents checked two or more choices, the answer was voided. The relationship between answers in the earlier period and patients' background, including age, sex, and tumor stage was analyzed. The frequency distributions were tested by the $\chi^{2}$ test, Fisher's exact test, or Mann-Whitney's $U$-test. A $P$ value of less than 0.05 was considered significant.

\section{Results}

We received answers from 67 patients; 46 in the earlier period and 21 in the later period.

\section{Did the patients read and understand the GLs?}

Nearly $90 \%$ of the patients answered that they had read almost all of the GLs (Table 1). Nearly $60 \%$ of the patients answered that they understood almost all of the content, and the proportion exceeded $80 \%$ when the patients who understood more than half of the content were included (Table 2). Although patients under age 60 years tended to have read and understood the GLs more than the patients aged 70 or older, there was no significant difference between these groups (Tables 1 and 2). When asked, "Did you have any knowledge of the content of the GLs before you read them?", only $9 \%$ of the patients knew more than half of the content of the GLs, and $43 \%$ of the patients had had no knowledge of the content of the GLs (Table 3).
How did the patients evaluate the GLs?

Nearly $70 \%$ of the patients answered that it was very useful for them to read the GLs before treatment (Table 4). On the other hand, $34 \%$ of the patients suggested negative aspects of reading the GLs. The most common negative aspect was that anxiety about the disease or treatment had increased (Table 5). The answers to these questionnaires did not vary according to age, sex, or stage of disease (Tables 4 and 5).

\section{Did the patients expect treatment that followed the GLs?}

Only $9 \%$ of the patients expected treatment that followed the GLs, whereas $54 \%$ of the patients expected treatment based on the doctor's own experience without adherence to the GLs (Table 6). To the question "How would you respond if your doctor offered treatment that did not follow the GLs?", $87 \%$ of the patients answered that they would follow the doctors' suggestion, and it was only $8 \%$ who answered that they would seek a second opinion (Table 7). These results did not differ when patients were requested to fill out questionnaires anonymously. The attitude of following the doctor's experience and suggestions rather than the GLs tended to be more prominent in patients aged 70 or older than in younger patients, although the difference was not statistically significant (Tables 6 and 7).

\section{Discussion}

Most of the patients, even the elderly, had read and understood the GLs for popular use. Thus, the GLs seemed to be well written and easy to understand for the general public. Arai et al. [4] have reported similar 
results with a questionnaire survey. More than $90 \%$ of the patients, however, had no or only a little knowledge about the content of the GLs before they read them. Thus, it is important to provide the patients with enough information about the disease and the treatment modalities. As a matter of fact, most of the patients considered it useful to read the GLs before receiving treatment.

Some negative aspects of reading the GLs were also revealed. A fourth of the patients considered that reading the GLs increased their anxiety about the disease or the treatment. Color illustrations, detailed descriptions of surgical procedures and postoperative complications, and survival rates may help patients understand their disease and the treatment, on one hand, but may, on the other hand, cause anxiety. A psychological approach may be necessary to reduce patients' anxiety or to select those patients who should be informed in another way.

Despite the fact that most of the patients had read and understood the GLs, more than half of the patients expected treatment based on the doctor's own experience rather than treatment following the GLs. Moreover, nearly $90 \%$ of the patients answered that they would follow the doctor's suggestion, and fewer than $10 \%$ said they would seek a second opinion if the doctor suggested treatment that did not follow the GLs. Background factors of the patients, including age, sex, and stage of disease, had no significant impact on these answers. The responses to questionnaire studies such as these tend to be biased when respondents are identified by the doctors in charge. Therefore, questionnaires were filled out anonymously in the later period so that we could not identify the respondents. However, the results were not different from those in the earlier period. The relationship between doctors and patients may also vary according to the locality. Our hospital is located in a suburban area, about an hour by train from the center of Tokyo, Japan. The results might be somewhat different if a questionnaire survey were conducted in an urban area. Although the doctor-patient relationship has recently changed in Japan, the majority of patients still seem to depend heavily on the doctor that they first met, and are reluctant to seek a second opinion.

In conclusion, although the GLs for popular use are useful to provide gastric cancer patients with information concerning the disease and the treatment modalities, they may not have a great impact on patients' decisions about treatment. Another educational approach may be necessary to create a more mature doctor-patient relationship. We should also provide circumstances in which it is easy for patients to seek a second opinion.

\section{References}

1. Japanese Gastric Cancer Association. Gastric cancer treatment guidelines for doctors' reference (in Japanese). Tokyo: Kanehara; 2001.

2. Japanese Gastric Cancer Association. Gastric cancer treatment guidelines for popular use (in Japanese). Tokyo: Kanehara; 2001.

3. Japanese Gastric Cancer Association. Introduction to JGCA gastric cancer treatment guidelines. www.jgca.jp/PDFfiles/E-gudeline. PDF

4. Arai K, Iwasaki Y, Kimura Y, Takahashi Y, Yamaguchi T, Honma $\mathrm{S}$, et al. Practical use of the commentary book on gastric cancer treatment guidelines and the problems to be revised (in Japanese). J Clin Surg 2002;57:1623-8. 